\title{
Research Article \\ Effect of Modified Rubber Particles Mixing Amount on Properties of Cement Mortar
}

\author{
Gang Xue and Mei-ling Cao \\ Architecture and Civil Engineering, Inner Mongolia University of Science and Technology, Baotou 014010, China \\ Correspondence should be addressed to Mei-ling Cao; caomeiling_2015@126.com
}

Received 1 December 2016; Accepted 4 January 2017; Published 29 January 2017

Academic Editor: Peng Zhang

Copyright (C) 2017 Gang Xue and Mei-ling Cao. This is an open access article distributed under the Creative Commons Attribution License, which permits unrestricted use, distribution, and reproduction in any medium, provided the original work is properly cited.

The crumb rubber cement mortar is prepared by the crumb rubber aggregates in 60 mesh which are modified by $1 \%$ polyvinyl alcohol (PVA) solution. Some mechanical properties of cement mortar with different crumb rubber aggregate amounts are researched including compressive strength, flexural strength, the ratio of compressive strength to flexural strength, impact resistance, and dry contraction percentage. In our tests, we consider six kinds of the rubber contents, $0 \%, 7.5 \%, 15 \%, 19 \%, 22.5 \%$, and $30 \%$, respectively. The optimal mixing amount of crumb rubber is determined by measuring three indices, the ratio of compressive strength to flexural strength, impact resistance, and dry contraction percentage. It is shown by test that the ratio of compressive strength to flexural strength is the smallest when the mixing amount of rubber is 19\%; meanwhile high impact resistance and rational drying shrinkage are observed. The optimal mixing amount of the rubber particles is $19 \%$ determined by this test.

\section{Introduction}

With the rapid development of the automobile industry in recent years, there is a large increase of waste tires. The world has more than one billion tires every year. About $21 \%$ of these waste tires have been recycled into civil engineering applications, to be used as modifiers or additive in asphalt paving mixtures and portland cement concrete (PCC) mixtures [1]. Potential uses of rubber modified cement mortar have also been reported. Now, mortar is widely applied to decoration engineering, such as ground surface and wall surface. Water retention and cohesiveness of traditional mortar are poor. Before the mortar hardened, the water evaporation rate of its surface is faster than the rate of internal bleeding, producing shrinkage stress in mortar. When shrinkage stress is greater than tensile strength, it will produce shrinkage cracking. In addition, after exposure in low humidity air for a longterm, cracks may be produced in surface mortar and as time goes by, the cracks deepen and widen gradually, and will seriously weaken concrete bonding property. In the 1970s, people began to study polymer mortar in order to improve the cracking resistance of traditional mortar. It is shown that the polymer mortar cannot meet the operating requirements due to its weaknesses, such as high costs, poor bond behavior, and poor durability. There are many methods for improving the toughness of cement concrete, and among them, adding rubber particles in concrete has attracted the attention of many scholars and become a research hot topic.

Tests by Segre and Joekes [2] showed that the bond force between rubber particles and cement-based materials will improve after modification by $\mathrm{NaOH}$ [3]. The flexural strength, compressive strength and fracture energy of the modified rubber particles mortar will improve. The experimental study by Benazzouk et al. [4] found that when the mixing amount changes between $15 \%$ and $35 \%$, the flexural strength has increased to varying degrees, while the compressive strength has decreased. The failure mode presents plastic instead of brittle when the mixing amount is more than $10 \%$. Sangson et al. [5] reported that the concrete mixed with rubber particles coming from waste tire makes the compressive strength and the elastic modulus slightly decreased, but at the meantime the curvature ductility increased by $90 \%$. Adding rubber particles into cement mortar is rarely reported, but it can be predicted that adding appropriate 
TABLE 1: The chemical composition of cement.

\begin{tabular}{lccccccc}
\hline The chemical composition & $\mathrm{SO}_{3}$ & $\mathrm{MgO}$ & $\mathrm{Na}_{2} \mathrm{O}$ & $\mathrm{K}_{2} \mathrm{O}$ & $\mathrm{Cl}^{-}$ & $\mathrm{f}-\mathrm{CaO}$ & Loss on ignition \\
\hline Content (\%) & 2.37 & 2.25 & 0.11 & 0.76 & 0.012 & 0.78 & 1.66 \\
\hline
\end{tabular}

TABLE 2: The physical properties of cement.

\begin{tabular}{lccccc}
\hline $\begin{array}{l}\text { The standard consistency water } \\
\text { quantity }(\%)\end{array}$ & $\begin{array}{c}\text { Density } \\
\left(\mathrm{g} / \mathrm{cm}^{3}\right)\end{array}$ & $\begin{array}{c}\text { Loss on ignition } \\
(\%)\end{array}$ & $\begin{array}{c}\text { Content of } \mathrm{SO}_{3} \\
(\%)\end{array}$ & $\begin{array}{c}\text { Stability (boiling } \\
\text { method) }\end{array}$ & $\begin{array}{c}\text { Setting time } \\
\text { Initial setting }\end{array}$ \\
\hline 28.4 & 2.89 & 2.26 & 2.37 & Final setting \\
\hline
\end{tabular}

amounts of rubber particles can improve toughness, sound absorption and insulation, and impact resistance of cementbased materials [6].

By antitheses test, research is done on the influence of modified rubber particle mixing amount [7-9] on the flexural strength, compressive strength, the ratio of compressive to flexural strength, impact resistance, and dry contractibility of cement mortar.

\section{The Composition of Raw Material}

2.1. Cement. The P.O42.5 ordinary portland cement is used in the test; the chemical composition of cement is shown in Tables 1 and 2.

2.2. Sand. The bulk density is $1592 \mathrm{~kg} / \mathrm{m}^{3}$, the mud content is $8.9 \%$, and the fineness modulus is 2.2 .

2.3. Rubber Particle. The size of regenerated rubber particle is 60 mesh, and the bulk density is $290.1 \mathrm{~kg} / \mathrm{m}^{3}$.

2.4. Mix Design. Quantity ratio of cement and sand is $1: 2.8$, with consistency varied $7 \sim 8 \mathrm{~cm}$. Rubber particles float upward in the cement mortar when consistency is too large. There is the problem of nonuniform mixing of rubber particles in the cement mortar when consistency is too small. Therefore, the viscosity of the mortar should be adjusted in the process of adding rubber; rubber aggregates are divided by adding several times. Crumb rubber aggregates in 60 mesh were modified by $1 \%$ polyvinyl alcohol (PVA) solution and used for preparing crumb cement mortar.

\section{The Test Method}

The compressive strength test, flexural strength test, impact resistance test, and drying shrinkage test were carried out in this paper. Three indices which are the ratio of compressive strength to flexural strength, impact resistance, and dry contraction percentage are used to determine the appropriate mixing amount of crumb rubber.

3.1. The Test of Compressive Strength and Flexural Strength. The specimens of crumb rubber aggregate cement mortar were $100 \mathrm{~mm} \times 100 \mathrm{~mm} \times 100 \mathrm{~mm}$ for cube compressive strength. According to the "Method of testing cementsDetermination of strength" (GB/T17671-1999) specification's making and measuring are to measure its compressive strength. The compressive strength of the mortar is in accordance with the polymer cement mortar specification of the "Technical specification for plasting mortar" (JGJ/T2202010). The specimens of prism flexural strength were $40 \mathrm{~mm}$ $\times 40 \mathrm{~mm} \times 160 \mathrm{~mm}$, and their flexural strength is determined. The specimens were cured in standard curing for 28 days. The ratio of compression strength to flexural strength cement mortar with different dosage of 60-mesh rubber particles was obtained.

3.2. The Test of Impact Resistance. Make crumb rubber cement mortar according to previously determined mix proportion, smear mortar on polystyrene board with size of $600 \mathrm{~mm} \times 250 \mathrm{~mm} \times 50 \mathrm{~mm}$ and apparent density of $(18.0 \pm$ 0.2 ), and the alkali resistance network cloth is pressed into the mortar. The surface mortar thickness is $3.0 \mathrm{~mm}$, and the alkali resistance network cloth is located $1.0 \mathrm{~mm}$ away from the surface mortar. Test procedures are as follows:

(1) Make surface mortar layer upward, putting it on the impact resilience tester horizontally and clinging to the basement.

(2) Let a steel ball whose nominal diameter is $50.8 \mathrm{~mm}$ impact test specimens in free fall from where the gravitational potential energy is $3.0 \mathrm{~J}$. Impacting five times at each level, interval among the impact points and the distance between the impact point and the edge of the pitch should be not less than $100 \mathrm{~mm}$. The annular crack around the impact point on the sample surface is regarded as the occurrence of impact damage. Specimen can be judged as no impact damage when the number of impact damage points in five tests is less than two and can be judged as impact damage when the number of impact damage points in five tests is not less than two.

(3) If specimen is not damaged, for the $3.0 \mathrm{~J}$ potential energy of the gravitational impact, test will be done on the sample while the impact gravitational potential energy is increased by $1.0 \mathrm{~J}$ until the sample is damaged. If the potential energy of the gravitational impact is more than $7.0 \mathrm{~J}$, the nominal diameter of $63.5 \mathrm{~mm}$ steel ball will be used.

(4) If specimen is damaged for the gravitational impact of 3.0 J potential energy, test will be done on the sample until the sample is damaged, while the gravitational potential energy is decreased by $1.0 \mathrm{~J}$. 
3.3. The Test of Dry Shrinking Performance. Put well-mixed crumb rubber mortar into $40 \mathrm{~mm} \times 40 \mathrm{~mm} \times 160 \mathrm{~mm}$ prismshaped test mould. The shrinkage head made of copper is fixed in the hole of two end surfaces of test mould, which is higher than the end of the test mould $8 \pm 1 \mathrm{~mm}$. Templates are removed when it has been cured under standard conditions for 7 days. The initial length of specimen is measured along the predetermined direction after being preset for 4 hours. Place the mortar specimens indoors with temperature of $20 \pm$ $2^{\circ} \mathrm{C}$ and relative humidity of $(60 \pm 5) \%$, and measure the length of the specimen at 7 days, 14 days, 21 days, 28 days, 56 days, and 90 days, respectively, by which the natural drying length of the specimen is obtained. The natural drying shrinkage value of the mortar is calculated according to

$$
\varepsilon=\frac{\left(L_{0}-L_{t}\right)}{\left(L+L_{d}\right)} .
$$

In the formula, $\varepsilon$ is natural drying shrinkage of specimens corresponding to the number of days; $L_{0}$ the original length of specimen cast mode for 24 hours when stripping $(\mathrm{mm})$; $L_{t}$ the measured length of specimens in $t$ days (mm); $L$ the standard length of specimens, $160 \mathrm{~mm}$; and $L_{d}$ the sum of the length of the two shrinkage heads, $20 \pm 2 \mathrm{~mm}$.

\section{Discussion of Results}

Different conclusions were drawn about the rubber's influence on concrete strength. Some results show [10] that rubber concrete flexural strength present the trend of increasing after reducing first with the increase of mixing amount of rubber particles, and other literature reports [11-13] that the flexural strength of cement concrete is always presents the tendency of decreasing with the increase of mixing amount of rubber particles. Research results all indicate that rubber particles can increase the toughness and deformation performance of cement concrete.

4.1. The Ratio of Compressive Strength to Flexural Strength. From Figure 1, it can be seen that the mortar compressive strength decreases when the percentage of crumb rubber increases. When the percentage of the rubber particles reaches $20 \%$, the compressive strength of mortar is about half the strength of the reference mortar sample. The test results about crumb rubber aggregate reducing mortar strength conforms to the related literature at home and abroad [14]. The main reasons leading to the decrease of the compressive strength of crumb mortar can be summarized as follows $[2,15]$ :

(1) Rubber particles are inert organic polymer material with no hydration activity, while cement materials are inorganic. Interfacial adhesion between rubber particles and cement materials is weak, resulting in strength reduction of mortar.

(2) The elastic moduli of rubber particles and cement materials differ greatly, and rubber particles cannot achieve the role of the skeleton. When rubber particle content is increased to a certain extent, it will cause

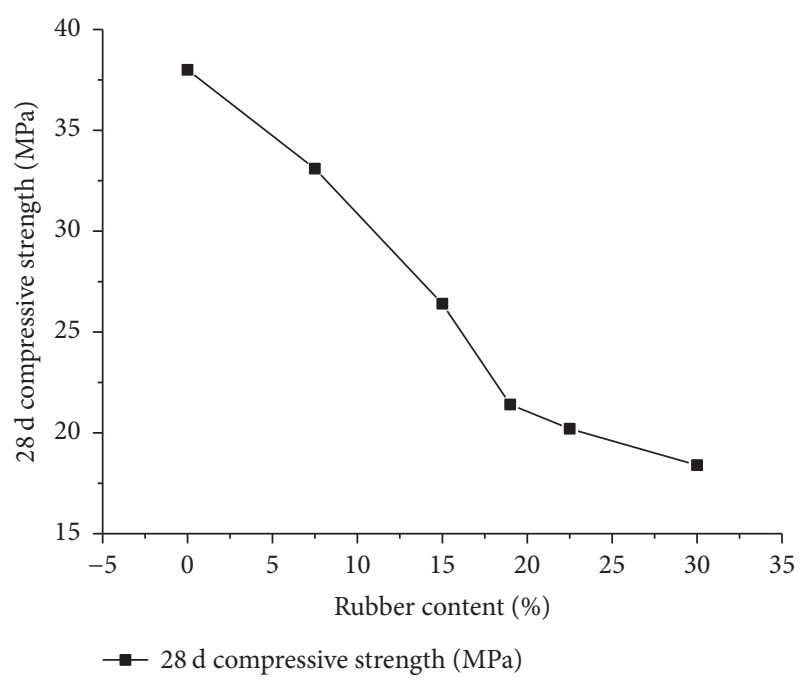

FIGURE 1: $28 \mathrm{~d}$ compressive strength of cement mortar with different amount of 60-mesh rubber particles.

internal structural discontinuity. The deformation between rubber particles and surrounding cementbased materials is inconsistent under the exterior load, resulting in strength reduction of the rubber cement mortar.

(3) There are some pores with different sizes in cement mortar. Smaller mixing amount of rubber granules may fill the pore and improve the density of mortar which result in the increase of compressive strength. When the mixing amount exceeds the maximum of the pore, compressive strength will be weakened [8].

As depicted in Figure 2, the flexural capacity of mortar decreases with the increase of rubber aggregate content for the similar reason to the decrease of compressive strength. While, the plaster mortar is not a load-bearing structure, so the compressive strength and flexural strength may not be as major considerations for mortar performance. According to the strength consequences of the tests, the ratio of compressive strength to flexural strength of the rubber particles cement mortar can be calculated, which is an index of the detection of cracking mortar, and the smaller ratio of compressive strength to flexural strength is, the better mortar toughness could be indicated. Toughness is an ability of energy absorption by which the materials or structures deform plastically and fracture against the exterior load until failure. Material toughness is not only related to capacity, but also to deformability. Figure 3 shows the extent decreasing of the ratio of compressive strength to flexural strength, with the rubber mixing amount of $15 \%$ to $19 \%$. When the rubber content is higher than $19 \%$, in contrast, it has an upward tendency. It shows that the toughness of cement mortar is greatly improved by the addition to rubber particles. Rubber particles are elastomers which play the role of microelastic bodies in the cement mortar, helpful to absorb the strain energy and improve the deformability and toughness of cement mortar. The rubber particle shows great ability of 


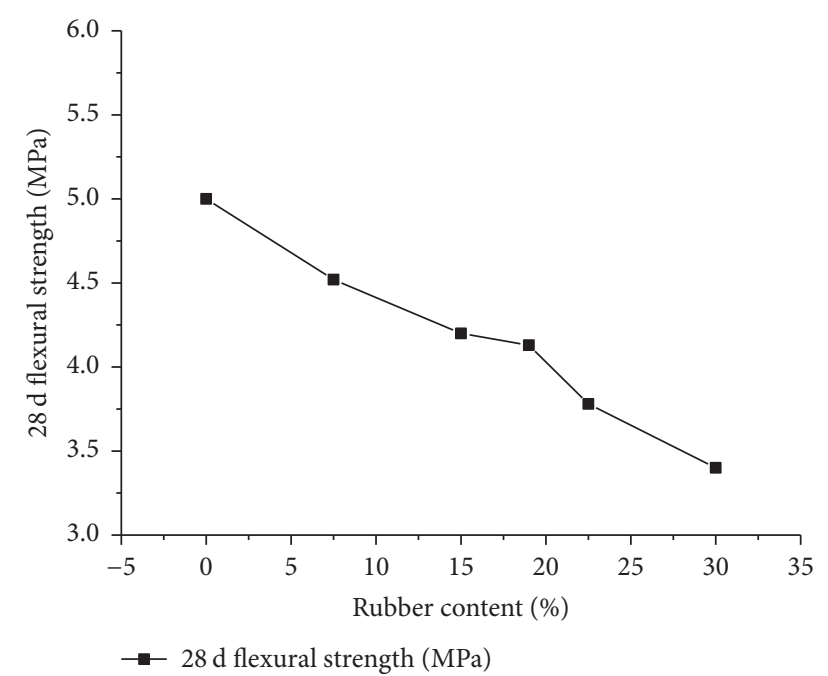

Figure 2: $28 \mathrm{~d}$ flexural strength of cement mortar with different amount of 60-mesh rubber particles.

deformation to accumulate large amount of strain energy when subjected to external loads for the reason of low elastic modulus. Mortar mixed with rubber particles can better maintain intact form and produce no sound of splitting, showing better elastic deformation capability during the test of compressive strength, as shown in Figure 4. While the cracks in the reference mortar base expanded and broadened rapidly after their appearance, brittle damage in the specimen occurred and sound can be heard when broken; failure feature is shown in Figure 5. In the flexural strength tests, reference mortar ruptured quickly and completely, as shown in Figure 6. while mortar mixed with rubber particles did not completely broken but partially bonded together when damaged, as shown in Figure 7. Researchers at home and abroad conducted many experimental studies for concrete or mortar mixed with fiber, and many achievements have been put into use in practical engineering fields [16]. In contrast, the research of concrete or mortar mixed rubber particles still in the experimental stage and failure mechanism of the concrete or mortar mixed with rubber particles are similar with those of the fiber concrete or mortar.

\subsection{The Impact Resistance and Dry Shrinking Performance}

4.2.1. The Impact Resistance. The impact resistance is an ability to resist material crack development and brittle fracture under external impact, which is an embodiment of its crack resistance. Researches at home and abroad show that the impact resistance of cement mortar improved with rubber particles added [17]. The impact resistances of 60-mesh rubber particles under different mixing amounts of cement mortar are shown in Figure 8. When the mixing amount of rubber particles is low, the improvement on impact resistance is not obvious because of the limited energy absorption of the mortar and the brittle failure mode. With the increase amount of rubber particles, impact resistance is enhanced gradually. Rubber particles in the cement mortar deform

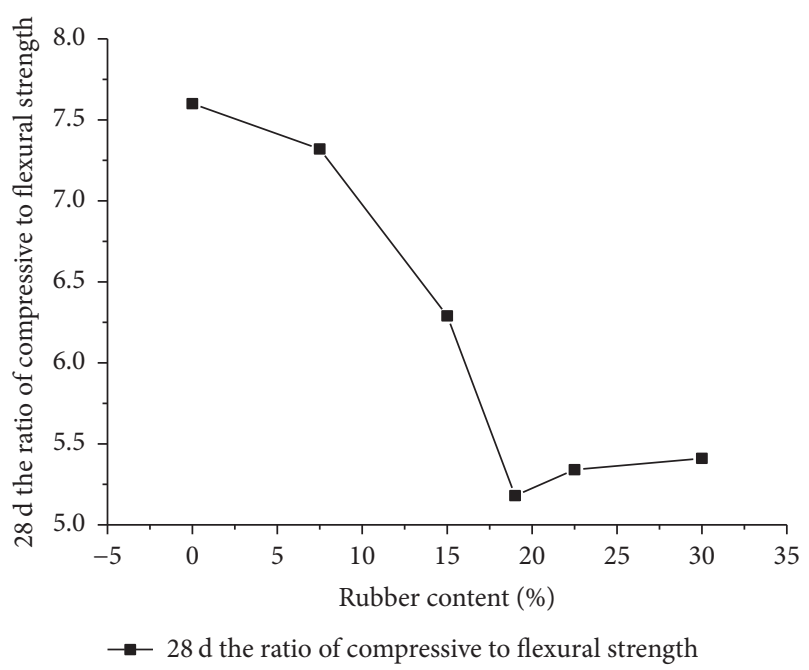

FIGURE 3: $28 \mathrm{~d}$ the ratio of compressive to flexural strength with different amount of 60 -mesh rubber particles.

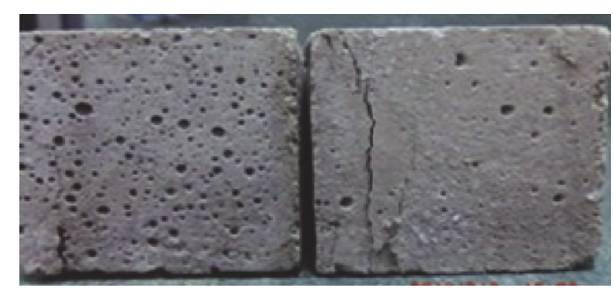

FIGURE 4: Mortar mixed with rubber particles compressive failure mode.

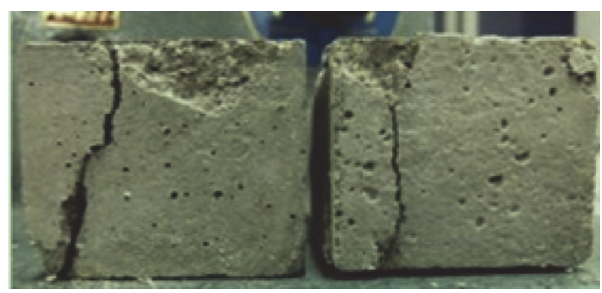

Figure 5: Reference mortar compressive failure mode.

elastically under external loads, which is not easy to produce brittle failure. It is to improve the impact resistance of mortar which is feasible in the mortar mixed with waste tire rubber particles.

4.2.2. The Dry Shrinking Performance. After the termination of maintenance, the gel pores and capillaries of the internal crumb rubber mortar block lost absorbed water in dry air, producing irreversible drying shrinkage. The drying shrinkage mechanism of cement mortar (concrete) mixed with rubber particles is more complex [18]. There are some main illustrations about it.

(1) Capillary Tension Theory. At low temperatures, meniscus is formed when the water surface in capillary declines, forming capillary pressure under tension of water. When the water 

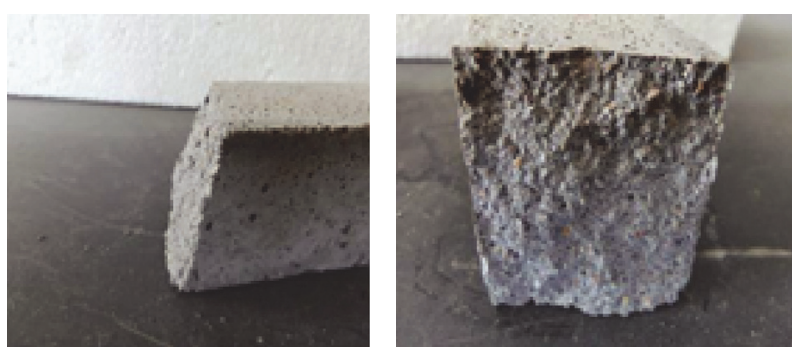

FIGURE 6: Reference mortar flexural failure mode.
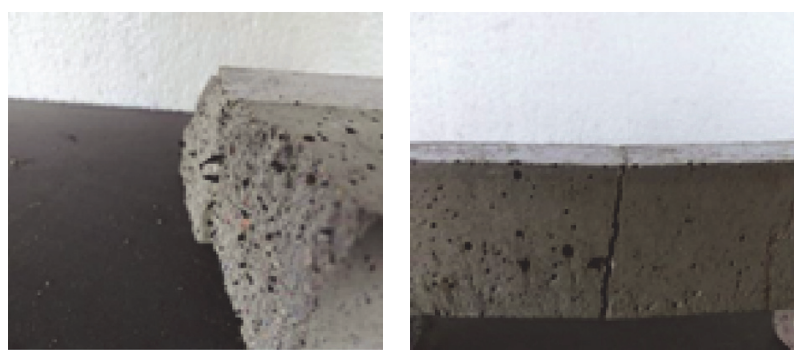

FIGURE 7: Mortar mixed with rubber particles flexural failure mode.

inside the capillary evaporates, mortar is in compression state, forming drying shrinkage.

(2) Disjoining Pressure Theory. Water absorbs on the surface of $\mathrm{C}-\mathrm{S}-\mathrm{H}$ and produces disjoining pressure at any temperature. If environmental temperature is low and the disjoining pressure is smaller than Van Der Waals force, the micromaterial will aggregate and cause contraction in volume.

Drying shrinkage deformation of cement mortar mixed with different amounts of 60-mesh rubber particles is shown in Figure 9. Drying shrinkage of mortar changed little when the mixing amount of rubber particles is less [19]. The rubber particle is elastomer with small elastic modulus, whose constraint force is relatively small compared with the shrinkage stress of the cement paste [6].

Drying shrinkage of mortar improved significantly with the increment of the mixing amount of rubber particles. Rubber particles are hydrophobic substances, and a layer of water film can easily be formed on the surface of rubber particles when mixed with cement mortar. One part of the surface water is consumed in the course of cement hydration, and the rest free water evaporates in dry environment after maintenance terminated. When the mix amount of rubber particle is increased, the amount of evaporated free water is enlarged accordingly and drying shrinkage became more severer.

\section{Conclusions}

The surface layer is not a load-bearing part; on the premise of meeting the basic strength requirements, toughness can be considered as the main performance index of mortar. Though rubber particles reduce the compressive strength and the flexural strength of surface mortar, but the ratio of compressive strength to flexural strength is decreased, and

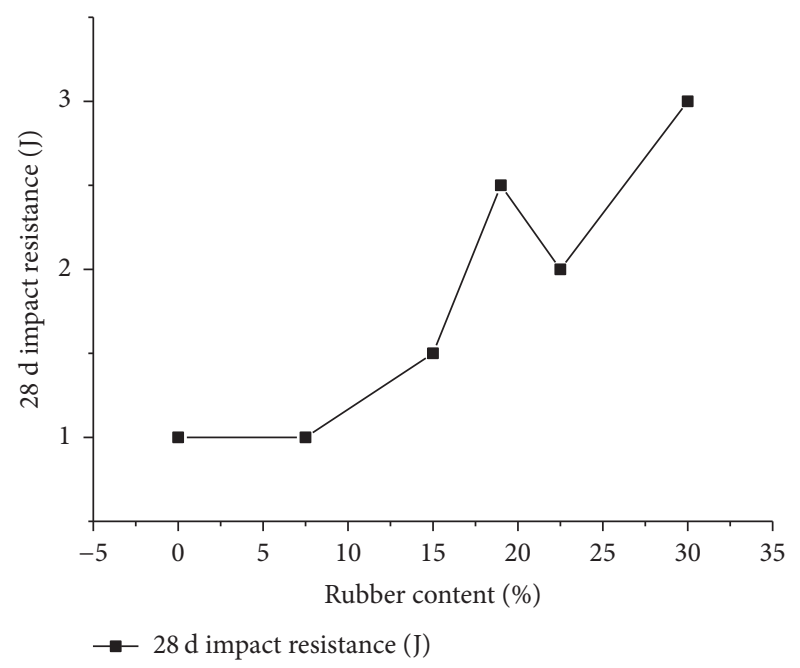

FIGURE 8: $28 \mathrm{~d}$ the impact resistance of cement mortar with different amount of 60-mesh rubber particles.

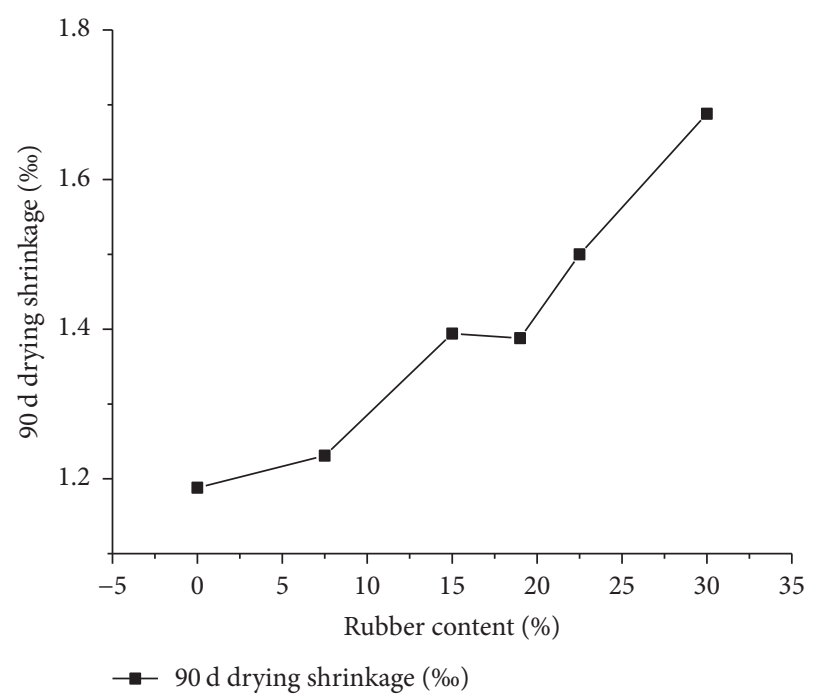

FIGURE 9: $90 \mathrm{~d}$ the drying shrinkage of cement with amount of 60mesh rubber particles mortar.

this indicates the mortar toughness is improved. Cement mortar mixed with crumb rubber can be used for the surface engineering, which may solve the problem that the crack resistance is poor in traditional surface mortar. According to the tests, the ratio of compressive strength to flexural strength is the smallest when the mixing amount of rubber is $19 \%$; meanwhile impact resistance is high at this moment and drying shrinkage is rational, so the appropriate mixing amount of rubber particles determined by this test is $19 \%$.

\section{Competing Interests}

The authors (Gang Xue and Mei-ling Cao) declare that there is no conflict of interests regarding the publication of this article. 


\section{References}

[1] US Environmental Protection Agency, Scrap tires-basic information, July 2011.

[2] N. Segre and I. Joekes, "Use of tire rubber particles as addition to cement paste," Cement and Concrete Research, vol. 30, no. 9, pp. 1421-1425, 2000.

[3] N. Segre, P. J. M. Monteiro, and G. Sposito, "Surface characterization of recycled tire rubber to be used in cement paste matrix," Journal of Colloid and Interface Science, vol. 248, no. 2, pp. 521523, 2002.

[4] A. Benazzouk, K. Mezreb, G. Doyen, A. Goullieux, and M. Quéneudec, "Effect of rubber aggregates on the physicomechanical behaviour of cement-rubber composites-influence of the alveolar texture of rubber aggregates," Cement and Concrete Composites, vol. 25, no. 7, pp. 711-720, 2003.

[5] K. Sangson, L. Hajirasouliha, and K. Pilakoutas, "Strength and deformability of waste tyre rubber-filled reinforced concrete columns," Construction and Building Materials, vol. 25, no. 1, pp. 218-226, 2011.

[6] A. Turatsinze, S. Bonnet, and J.-L. Granju, "Potential of rubber aggregates to modify properties of cement based-mortars: improvement in cracking shrinkage resistance," Construction and Building Materials, vol. 21, no. 1, pp. 176-181, 2007.

[7] B. Huang, X. Shu, and J. Cao, "A two-staged surface treatment to improve properties of rubber modified cement composites," Construction and Building Materials, vol. 40, pp. 270-274, 2013.

[8] A. Turatsinze, S. Bonnet, and J.-L. Granju, "Mechanical characterisation of cement-based mortar incorporating rubber aggregates from recycled worn tyres," Building and Environment, vol. 40, no. 2, pp. 221-226, 2005.

[9] Y. Akkaya, C. Ouyang, and S. P. Shah, "Effect of supplementary cementitious materials on shrinkage and crack development in concrete," Cement and Concrete Composites, vol. 29, no. 2, pp. 117-123, 2007.

[10] A. R. Khaloo, M. Dehestani, and P. Rahmatabadi, "Mechanical properties of concrete containing a high volume of tire-rubber particles," Waste Management, vol. 28, no. 12, pp. 2472-2482, 2008.

[11] N. Ganesan, J. Bharati Raj, and A. P. Shashikala, "Flexural fatigue behavior of self compacting rubberized concrete," Construction and Building Materials, vol. 44, pp. 7-14, 2013.

[12] H. Su, J. Yang, T.-C. Ling, G. S. Ghataora, and S. Dirar, "Properties of concrete prepared with waste tyre rubber particles of uniform and varying sizes," Journal of Cleaner Production, vol. 91, pp. 288-296, 2015.

[13] J. Lv, T. Zhou, Q. Du, and H. Wu, "Effects of rubber particles on mechanical properties of lightweight aggregate concrete," Construction and Building Materials, vol. 91, pp. 145-149, 2015.

[14] X. Shu and B. Huang, "Recycling of waste tire rubber in asphalt and portland cement concrete: an overview," Construction and Building Materials, vol. 67, pp. 217-224, 2013.

[15] H. Zhu, N. Thong-On, and X. Zhang, "Adding crumb rubber into exrerior wall materials," Waste Management and Research, vol. 20, no. 5, pp. 407-413, 2002.

[16] J.-H. Xie, Y.-C. Guo, L.-S. Liu, and Z.-H. Xie, "Compressive and flexural behaviours of a new steel-fibre-reinforced recycled aggregate concrete with crumb rubber," Construction and Building Materials, vol. 79, pp. 263-272, 2015.

[17] D. Sufen and H. Zhide, "Waste tire rubber particles in outer wall external thermal insulation mortar in the heating area in the application," Concrete and Cement Products, no. 5, pp. 48-52, 2011.

[18] Z. Xiling and Y. Ailing, "Study on mortar elastic modulus of slag cementitious materials," Journal of Silicate, vol. 30, no. 4, pp. 950-954, 2011.

[19] Y.-M. Zhang, S.-X. Chen, B. Chen, and W. Sun, "Dry shrinkage, frost resistance and permeability of rubber included concrete," Key Engineering Materials, vol. 302-303, pp. 120-124, 2006. 


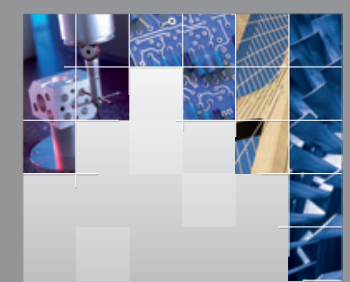

\section{Enfincering}
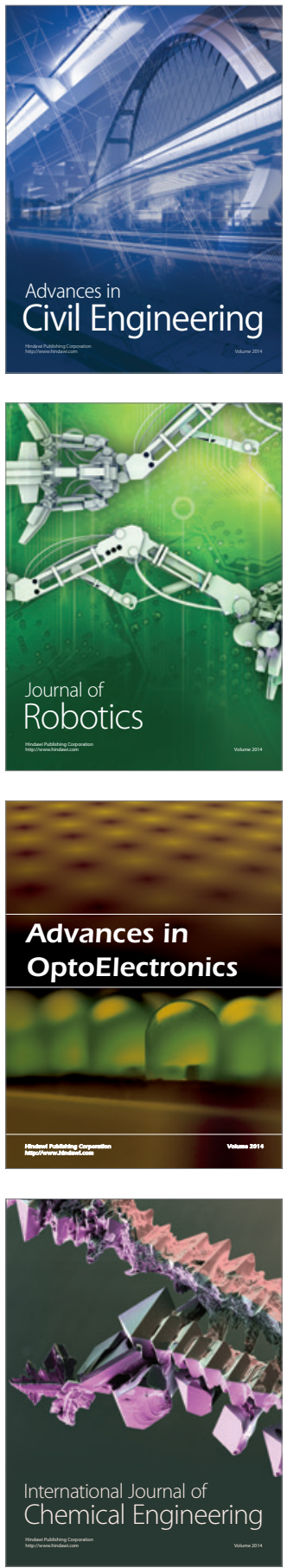

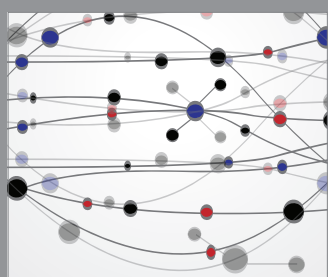

The Scientific World Journal

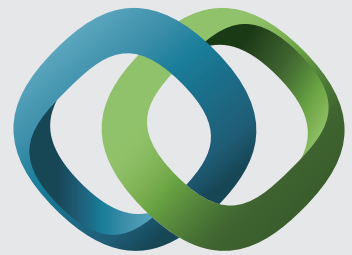

\section{Hindawi}

Submit your manuscripts at

https://www.hindawi.com
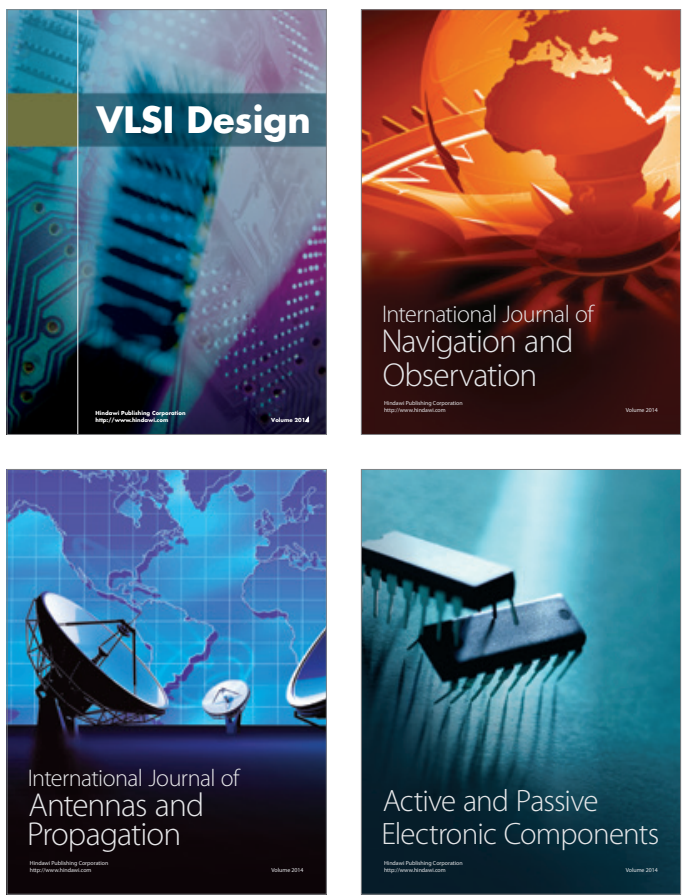
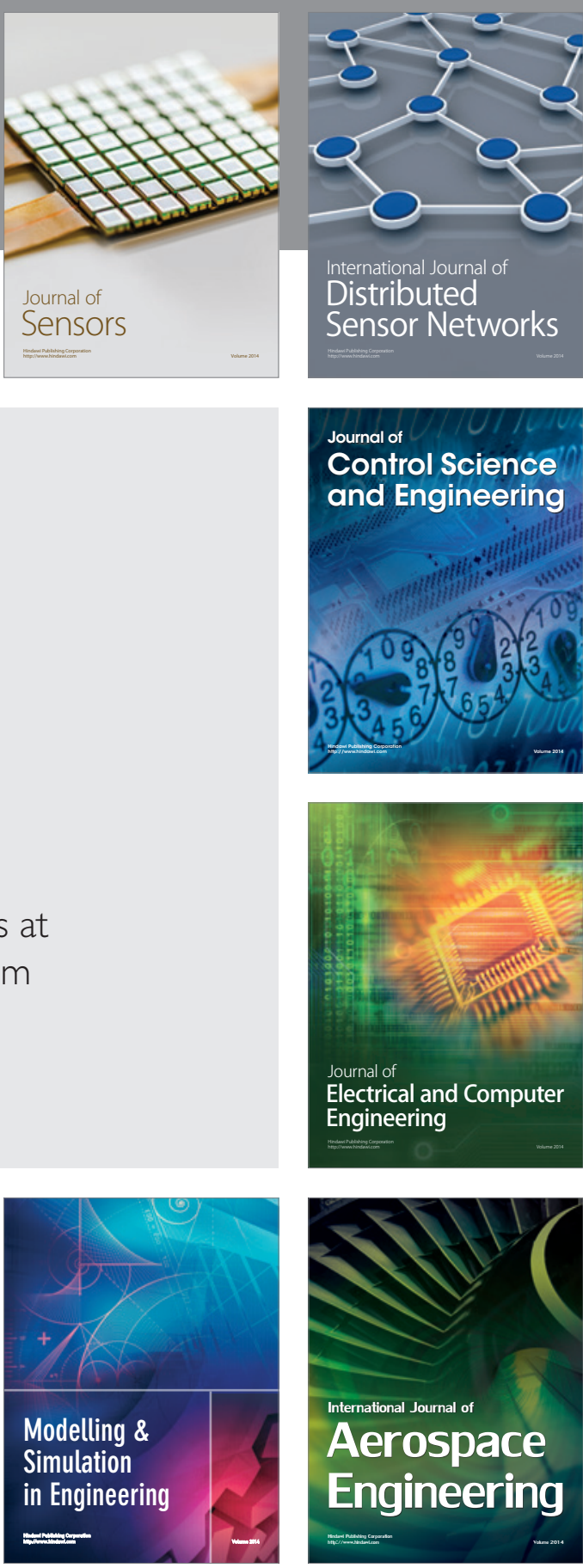

International Journal of

Distributed

Sensor Networks

$-$

Joumal of

Control Science

and Engineering
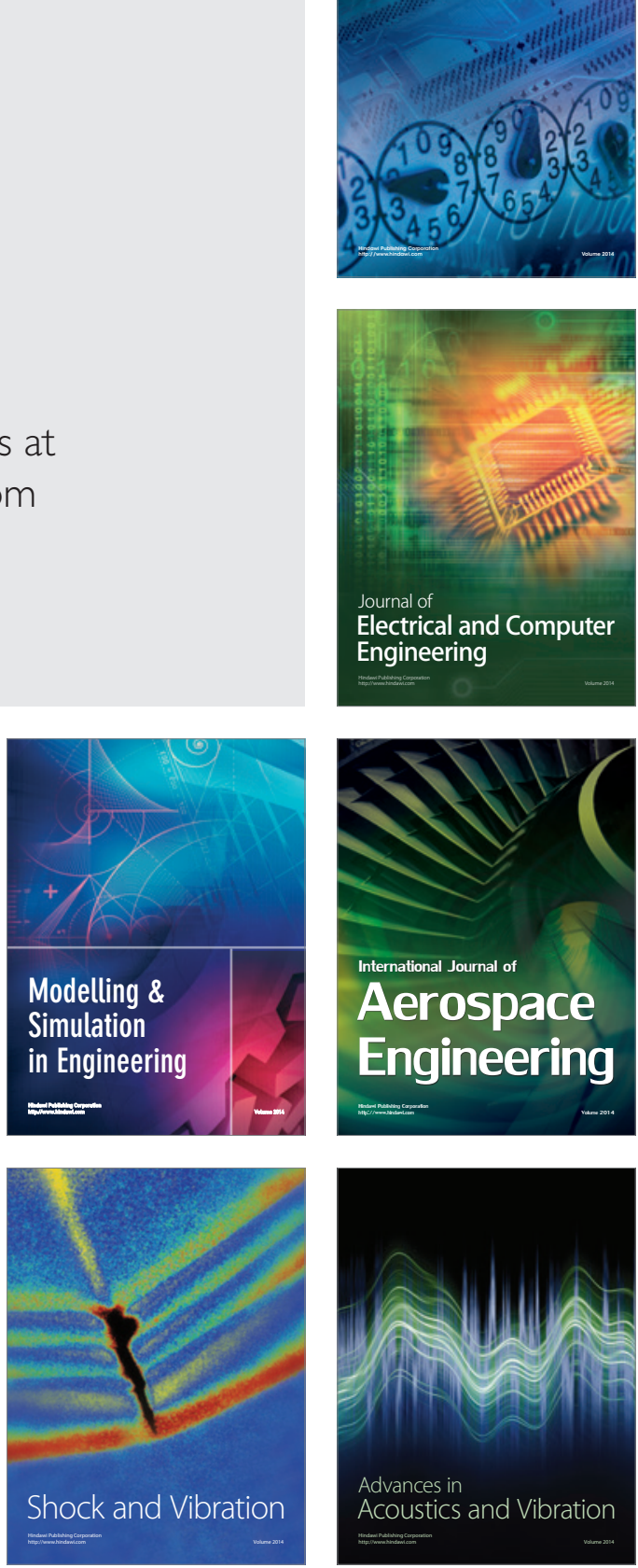